\title{
La arquitectura textual del carnaval en las columnas irónicas de Daniel Samper Ospina*
}

\author{
MIGUEL ÁNGEL CARO LOPERA ** \\ ZAHYRA CAMARGO MARTÍNEZ **** \\ GRACIELA URIBE ÁLVAREZ ****
}

Recepción: 3 de abril de 2017

Aprobación: 9 de marzo de 2018

Forma de citar este artículo: Caro, M. A.; Camargo, Z. \& Uribe, G. (2018). La arquitectura textual del carnaval en las columnas irónicas de Daniel Samper Ospina. Cuadernos de Lingüística Hispánica, (32), 41-59

\footnotetext{
* Este artículo de reflexión se deriva de la tesis doctoral, actualmente en construcción, "La comprensión de textos argumentativos irónicos: hacia una didáctica de la ironía”, dirigida por las doctoras Zahyra Camargo Martínez y Graciela Uribe Álvarez. Doctorado en Ciencias de la Educación, Universidad del Quindío, Rudecolombia.

** Magíster en Lingüística (Universidad Tecnológica de Pereira) y candidato a Doctor en Ciencias de la Educación (Universidad del Quindío, RUDECOLOMBIA). Profesor del Programa de Español y Literatura y miembro del grupo de investigación DiLeMa (Didáctica de la Lengua Materna y la Literatura), Universidad del Quindío. Correo electrónico: macaro@uniquindio.edu.co

*** Doctora en Didáctica de las Lenguas y la Literatura de la Universidad Complutense de Madrid. Profesora titular del Programa de Español y Literatura, directora de la Maestría y del Doctorado en Ciencias de la Educación, y coordinadora del grupo de investigación DiLeMa (Didáctica de la Lengua Materna y la Literatura), Universidad del Quindío. Correo electrónico: zcamargo@uniquindio.edu.co

***** Doctora en Didáctica de las Lenguas y la Literatura de la Universidad Complutense de Madrid. Profesora titular del Programa de Español y Literatura, de la Maestría y del Doctorado en Ciencias de la Educación, y co-fundadora del grupo de investigación DiLeMa (Didáctica de la Lengua Materna y la Literatura), Universidad del Quindío. guribe@uniquindio.edu.co
} 


\title{
Resumen
}

Este artículo de reflexión, derivado de una tesis sobre la enseñanza de la comprensión de textos argumentativos irónicos, aborda, a la luz del interaccionismo sociodiscursivo, la posible arquitectura textual carnavalizada que se desprende de un corpus de 117 columnas de opinión de Daniel Samper Ospina publicadas entre 2014 y 2016 en la Revista Semana (Colombia). Desde un interés hermenéutico y perspectivas pragmalingüísticas para el estudio de la ironía verbal, se identifican rasgos de carnaval bajtiniano en los tres niveles de la infraestructura textual (gracias al juego con la dispositio argumentativa tradicional y al travestimiento de géneros), la textualización (mediante inversiones a los principios neogriceanos de Levinson, según el Grupo de la Ironía, Alicante, Lengua Española, Griale) y la responsabilidad enunciativa (como fruto de la inserción de enunciadores absurdos que enmascaran la función locutor). Esto refuerza la concepción de la ironía como dispositivo textual carnavalizante del decir, sus modos, sus voces y sus estructuras.

Palabras clave: ironía verbal, arquitectura textual, carnavalización, columnas de opinión.

\section{The textual architecture of the carnival}

\begin{abstract}
This reflection paper, derived from a thesis on the teaching of the understanding of ironic argumentative texts, addresses, in the light of socio-discursive interactionism, the possible carnavalized textual architecture that comes from a corpus of 117 opinion columns by Daniel Samper Ospina published between 2014 and 2016 in Semana Magazine (Colombia). From a hermeneutic interest and supported by pragmalinguistic perspectives of the study of verbal irony, traits of the "bajtianian carnival" are identified in the three levels of textual infrastructure (thanks to the traditional argumentative dispositio and the variety of genres), textualization (through investments in Levinson's neogritian principles, according to the Grupo de la Ironía, Alicante, Lengua Española, Griale) and the enunciative responsibility (as a result of the insertion of absurd enunciators that mask the speaker's function). This reinforces the conception of irony as a carnivalizing textual device of the action of saying, its modes, its voices and its structures.
\end{abstract}

Keywords: verbal irony, textual architecture, carnivalization, opinion columns. 


\section{L'architecture textuelle du carnaval dans les colonnes ironiques de Daniel Samper-Ospina}

\section{Résumé}

Cet article de réflexion, issu d'une thèse sur l'enseignement de la compréhension de textes argumentatifs ironiques, aborde, à la lumière de l'interactionnisme sociodiscursif, la possible architecture textuelle carnavalisée qui est dégagée d'un corpus de 117 colonnes d'opinion de Daniel Samper-Ospina, publiées entre 2014 et 2016 dans la Revue Semana (Colombie). À partir d'un intérêt herméneutique et des perspectives pragma-linguistiques pour l'étude d l'ironie verbale, on identifie des traits de carnaval bakhtinien dans les trois niveaux de l'infrastructure textuelle (grâce au jeu avec la dispositio argumentative traditionnelle et au déguisement de genres), la textualité (au moyen des investissements aux principes « neogriceanos » de Levinson, selon le Groupe de l'Ironie, Alicante, Langue Espagnole, Griale) et la responsabilité énonciative (comme produit de l'insertion des énonciateurs absurdes qui camouflent la fonction locuteur). Ceci renforce la conception de l'ironie en tant que dispositif textuel carnavalisant du dire, ses modes, ses voix et ses structures.

Mots clés : ironie verbale, architecture textuelle, carnavalisation, colonne d'opinion.

\section{A arquitetura textual do carnaval nas colunas irônicas de Daniel Samper Ospina}

\section{Resumo}

Este artigo de reflexão, derivado de uma tese sobre o ensino da compreensão de textos argumentativos irônicos, aborda, à luz do interacionismo sociodiscursivo, a possível arquitetura textual carnavalizada que emerge de um corpus de 117 colunas de opinião de Daniel Samper Ospina entre 2014 e 2016 na revista Semana (Colômbia). A partir de um interesse hermenêutico e perspectivas pragmalinguísticas para o estudo da ironia verbal, características do carnaval bakhtiniano são identificadas nos três níveis da infraestrutura textual (graças ao jogo com a tradicional argumentativa dispositio e ao transvesti mento de gêneros), a textualização (através de investimentos aos princípios neogriceanos de Levinson, segundo o Grupo Irony, Alicante, Língua Espanhola, Griale) e a responsabilidade enunciativa (como resultado da inserção de enunciadores absurdos que mascaram a função do falante). Isso reforça a concepção de ironia como um mecanismo textual carnavalizamte de dizer, seus modos, suas vozes e suas estruturas. opinião.

Palavras-chave: ironia verbal, arquitetura textual, carnavalização, colunas de 


\section{Introducción'}

Impulsados por investigaciones recientes que propician un ambiente investigativo favorable a la ironía verbal ${ }^{2}$ y en el marco de una tesis aún en construcción sobre la enseñanza de la comprensión de textos argumentativos irónicos, nos acercamos a la arquitectura textual que se desprende de la revisión de 117 columnas escritas por Daniel Samper Ospina entre el 2014 y 2016 en la Revista Semana (Colombia). Nos apoyamos, para el concepto de arquitectura textual, en los aportes del interaccionismo sociodiscursivo que la considera compuesta por tres niveles: la infraestructura textual (materialización lingüística de "mundos virtuales"), los mecanismos de textualización (series isotópicas que contribuyen a establecer la coherencia temática) y los mecanismos de asunción del compromiso enunciativo (instancias que asumen lo enunciado en el texto, a partir de las voces y las modalizaciones), (Bronckart, 2004, p. 15).

Optar por esta posibilidad teórica reviste cierta novedad en el estado del tema que, para el caso del género específico de la columna de opinión, recoge - hasta donde conocemos- pocos trabajos: el de Crespo (2008), el de Martínez-Egido (2014) y el de Mier (2017), en el que justamente se ocupa de un texto de Samper Ospina, "Lo que de verdad sucedió en el secuestro de Salud" de Samper-Ospina (Semana, 2016); allí describe la ironía verbal como fenómeno pragmático que se explica a partir del conocimiento del contexto, y concluye que "sin el conocimiento pleno de las situaciones extralingüísticas no es posible completar el sentido de un texto irónico" (Mier, 2017, p. 28).

De entrada, conviene aclarar que los textos de Samper Ospina presentan ironía continuada, aquella que no aparece necesariamente en un enunciado concreto (como ocurre con las ironías focalizadas), sino a lo largo de todo un texto, para lo cual no siempre se vale de indicadores lingüísticos (Ruiz-Gurillo, Marimón-Llorca, PadillaGarcía \& Timofeeva, 2004). Esto eleva la complejidad de comprensión, ya que, como declara Boyd-Swan (2009), "no existen en el lenguaje escrito indicadores explícitos y unívocos de la ironía que correspondan al señalamiento que el lenguaje del cuerpo lleva a cabo en la conversación" (p. 304).

\footnotetext{
${ }_{1}$ Agradecemos al jurado que evaluó este artículo, en calidad de par ciego, por sus puntuales y pertinentes observaciones.

2 Para mayores detalles sobre este estado del tema, se puede consultar el artículo de revisión publicado por los autores, "La ironía re-visitada en sus dimensiones pragmáticas, comprensivas, discursivas y didácticas" (Caro, Camargo \& Uribe, 2018).
} 
Por último, en relación con el título de este artículo, indicamos que la fuerza de los resultados recogidos nos ha llevado a arriesgar la idea de que en toda esta arquitectura textual subyace el fenómeno de la carnavalización, en el sentido bajtiniano "de transposición del carnaval" (Bajtín, 1976, p. 312). En efecto, y a pesar de movernos en un género no literario (aunque un $7.5 \%$ del corpus se acerque a géneros como el cuento, el teatro y la poesía), aspiramos a extender el concepto hasta estas columnas de opinión, amparados en los lazos de familia entre carnaval e ironía que el mismo Bajtín (1976) reconocía, cuando hablaba de la ironía socrática como "risa carnavalesca reducida” (p. 328). A la luz de todas estas consideraciones, estructuraremos el artículo de acuerdo con los tres niveles antes referidos e intentaremos ilustrar con diversas citas los hallazgos conseguidos.

\section{La infraestructura textual}

Asevera Bronckart (2004) que este nivel, el más profundo de la arquitectura textual, "está constituido por el plan general del texto, por los tipos de discurso que comporta, por las modalidades de articulación de esos tipos de discurso y por las secuencias que eventualmente aparecen en él” (p. 76). Para el propósito sucinto de este artículo, nos interesa de este nivel la caracterización del género discursivo y de la tipología textual presentes en la muestra, pues, contrario a lo que podría pensarse, el comportamiento en este sentido no es homogéneo. Si echamos mano, por ejemplo, de la clasificación que Dolz y Schneuwly (1997) -como representantes del interaccionismo sociodiscursivo- proponen al respecto, las columnas de opinión estudiadas se escapan de la categoría que, a priori, podríamos señalar para ellas: textos argumentativos, inscritos en el ámbito social de las "discusiones de problemas sociales controvertidos", en los que se ponen en juego las capacidades lingüísticas del "afianzamiento, refutación y negociación de toma de posición” (p. 90). Sin embargo, stricto sensu, a esta posibilidad solo se adscribe el $35 \%$ de los textos; en cambio, un $40.3 \%$ responde a la tipología del relatar, inserta -según Dolz y Schneuwly (1997)- en el ámbito social de la "documentación y memorización de acciones humanas" y que exige las capacidades lingüísticas de "representación mediante el discurso de experiencias vividas, situadas en el tiempo" (p. 90). De ahí que encontremos, en lugar de la típica columna esperada, noticias, reportajes, testimonios y crónicas mundanas y familiares. El narrar también hace presencia con un $7.5 \%$, mediante la inclusión de cuentos, obras de teatro y hasta una propuesta de himno nacional. Algo similar sucede con el describir (3.3\%), a través de cartillas, instrucciones y hasta contratos laborales; y el exponer (2.5\%), gracias a la inserción de clases magistrales y textos explicativos.

Esta observación arroja la presencia de dos tipos de dispositios: 1- una argumentativa canónica carnavalizada, presente en los 54 textos de esta tipología (en 
el marco de los géneros de columna de opinión tradicional, carta y obituario); y 2- una argumentativa travestida, presente en los 63 textos restantes, en la que las intenciones argumentativas se subvierten bajo las formas de otras tipologías, como el relatar, el narrar, el describir y el exponer.

\subsection{Una dispositio argumentativa carnavalizada}

Concebida por la Retórica Antigua como una de las cinco operaciones que movían la elaboración de un discurso (ubicada después de la inventio y antes de la memoria, elocutio y actio), la dispositio, como bien lo sabemos, se ocupa de la estructuración de los grandes bloques de ideas - de su armazón discursiva- en respuesta a imágenes mentales que se consolidan desde la tradición organizativa - eminentemente social- de cada género. Para el caso de la tipología textual argumentativa en la que se inscribe el 46 $\%$ de los textos analizados, se advierten las huellas de aquellas piezas discursivas que para los rétores formaban la dispositio: el exordio, la narratio, la argumentatio y la peroratio; sin embargo, revelan ciertos niveles de carnavalización que pretendemos describir a continuación, con la inserción, ad hoc, de un adjetivo que intente capturar el nuevo matiz que allí percibimos; hablaremos, entonces, de un exordio ponzoñoso, una narratio evaluativa, una argumentatio caricaturesca y una peroratio rizomática.

1.1.1 Un exordio ponzoñoso: ideado como lugar estratégico para captar la atención del auditorio, el exordio ha representado en la Retórica Antigua el punto clave para la presentación de la tesis, el posicionamiento del autor y la declaración de sus intenciones argumentativas. Podríamos decir que aquel principio que tanto ha pregonado la publicidad en términos de que no hay una segunda oportunidad para conseguir una primera buena impresión tiene su origen en las lecciones de los rétores alrededor de la función emotiva del exordio y de su inapelable obligación de tocar el pathos del auditorio, pues su finalidad - tal como lo define Albaladejo (1991) - es "la presentación de la causa ante el receptor y obtener su disposición favorable hacia el planteamiento que el orador hace" (p. 82). En el $66 \%$ de los textos revisados, el exordio, sin perder sus condiciones prototípicas, busca acentuar el efecto perlocutivo en el lector y lo pone en tensión, gracias a una posición exacerbada del locutor que expresa sin atenuantes su tesis, en lo que podríamos llamar actitud cáustica, mordaz, corrosiva, o mejor, ponzoñosa. Este rasgo se advierte, en virtud de la corta extensión de las columnas de opinión, en el título mismo: Informe del exorcismo a Paloma Valencia (27 de septiembre de 2014), Papa Francisco: no venga (11 de abril de 2015), Propuesta para desmovilizar al uribismo (15 de agosto de 2015), Cambio al fiscal por tres mulas (19 de marzo de 2016), entre otros. Incluso, más allá del título, el efecto mordaz puede prolongarse hasta las primeras oraciones del texto, tal como lo revela el siguiente ejemplo, apoyado en el anacronismo: 
Queridos estudiantes, bienvenidos a la Facultad de Ciencias de la Universidad de La Sabana. Soy monseñor Escrivá de Balaguer y seré su maestro de ceremonias en su primer día de esta nueva etapa de sus vidas. Como primera medida, les presento al decano de la Facultad, el exbailarín, exafro y exhomosexual, Nerú: todo un ejemplo de superación. De rodillas (Una inducción en la Sabana, 21 de febrero de 2015).

Con tal exposición de proemios cáusticos, pareciera invertirse aquel principio retórico del in cauda venenum, según el cual la mayor fuerza argumentativa se enseña al final, cuando se ha demostrado la viabilidad de los argumentos; más bien, al estilo del mundo al revés que supone el carnaval, el veneno nos llega desde el comienzo, como golpe al pathos, desde recursos irónicos textualizadores que exploraremos más adelante.

1.1.2 Una narratio evaluativa: erigida en la tradición retórica como el espacio para las secuencias expositivas que contextualizan al lector sobre el tema en torno al cual el autor eleva su postura, la narratio cumple el rol de activar la memoria de trabajo del receptor, pues solo desde esos escenarios compartidos es posible la comunicación argumentativa y, en últimas, su adhesión a la tesis. Esto determina que la narratio, por naturaleza, deba ser breve, clara y verosímil, con movimientos, por la línea lógica, hacia el logos del lector (Albaladejo, 1991, p. 86). Sin embargo, en el corpus escrutado, aparece una particularidad bien curiosa: la narratio es evaluativa, como en el siguiente ejemplo3:

[...] No sabía si sumarme a la campaña publicitaria 'Soy capaz' por considerarla sospechosa, y de hecho tengo un amigo abogado que piensa demandarla por abierta discriminación contra Pachito Santos y Andrés Pastrana. Pero decidí hacerlo luego de leer las declaraciones de Santiago Valencia en contra de la guerrillera holandesa Tanja Nijmeijer. Santiago Valencia, para quien no lo sepa, es hijo de Fabio Valencia Cossio, y, como consecuencia natural de ese hecho biológico, es congresista de Centro Democrático. Fabio es así. En la medida en que caen sus hermanos a la cárcel, mete en la política a sus hijos, y eso tiene un mérito (Soy capaz de apoyar 'Soy capaz', 20 de septiembre de 2014).

Así, en la explicación que contextualiza al lector sobre Santiago Valencia, el locutor evalúa desde la ironía (finamente emparentada con el argumento ad hominem) su procedencia y sus filiaciones, lo que se refuerza con el sarcasmo de la última oración adosado al reconocimiento antifrástico de sus méritos. Sin embargo, si volvemos a nuestra conjetura en torno a la carnavalización del texto, podemos apreciar cómo desde una narratio tan claramente evaluativa, el autor expresa aquello que Bajtin (1976) denominaba como actitud carnavalesca caracterizada por "un contacto libre y familiar" (p. 313). Parece, entonces, que no solo en la literatura, sino también en el periodismo irónico, se aplican las palabras de Bajtín (1976): "No se mira el carnaval y, para ser más

3 Aunque en muchos casos es difícil distinguir la narratio por su cercanía funcional al exordio y a la argumentatio, podríamos asegurar su presencia en, al menos, un $25 \%$ de los textos analizados. 
exactos, habría que decir que ni siquiera se lo representa, sino que se lo vive, se está plegado a sus leyes mientras estas tienen curso, y se lleva así una existencia de carnaval" (p. 312).

1.1.3 Una argumentatio caricaturesca: pensada como el corazón del discurso, la argumentatio, según su nombre lo indica, es el lugar por excelencia de la argumentación, una vez que hemos conocido la tesis del autor en su exordio y hemos activado nuestros conocimientos previos en la narratio. Allí, los ejemplos, las estadísticas, las analogías, las citas de autoridad y los datos finamente tejidos -por lo regular siguiendo una línea lógica y vigilantes de las falacias- apuntan a convencer al lector en un campo de batalla poblado, según Aristóteles, por pruebas extratécnicas, morales y lógicas, todas ellas de diverso poder suasorio (2005, pp. 105-280). Sin embargo, en los textos de Samper Ospina, la batalla parece librarse en el campo del pathos, gracias a mecanismos propios de la caricaturización, en respuesta al principio bergsoniano de que "nos reímos siempre que una persona nos causa la impresión de una cosa” (Bergson, 2008, p. 47). Esto se advierte, en el siguiente ejemplo, tanto en las hipérboles de [1] y [2], como en la polisemia de [3] y el sarcasmo de [4]:

[1] ¿Nombre? -Villegas, Luis Carlos ... - ¿Y por qué no tiene forma humana? -La tiene, capitán, sino que en el monitor apenas cabe el primer tercio abdominal... -Dudo que la nave consiga remontar vuelo con tanto sobrepeso, capitán... -Entonces tenemos este otro candidato... [2]-¿Nombre? -Santos. Juan Manuel Santos. Es su líder. -¿Este es su líder? Pues es un decir... Pero sí. -[3] ¿Y ha tenido encuentros del tercer tipo? -Pues el tercer tipo es el que puso en la terna de la Fiscalía: Néstor Humberto Martínez, pero no recomiendo abducirlo: es para líos, tiene demasiadas incompatibilidades éticas. [4] -¿Qué tantas? -Las suficientes para que lo nombren fiscal... (“iNo abduzcamos a Echeverry, sargento!”, 23 de abril de 2016).

Esta confluencia de procedimientos reductores de imagen discursiva arrastran a los personajes víctimas de la ironía hacia cierto tipo de entronización bufa, momento cumbre de todo carnaval. Mediante este juego de caricaturización, se definen las máscaras discursivas y los atavíos para el juego de escarnio. En este proceso gana la ironía su condición bivocal, ya que, como lo indica Bajtín (1976), "a través de la entronización se percibe ya la desentronización y esto se aplica a todos los signos carnavalescos: todos contienen en perspectiva la negación y su contrario" (p. 316).

En este orden de ideas, vale la pena reconocer la presencia de lo que podríamos llamar una digressio isotópica. Con el término digressio, nos referimos al excurso, como parte prescindible del discurso (a la par que la proposición y la enumeración) que, según Pujante (2003), "se sale del plan natural expositivo, pero que resulta útil a la causa y prepara para la probatoria que vendrá después" (p. 119). Con el término isotópica, resaltamos una cualidad muy importante de tales paréntesis discursivos y que nos 
recuerda el concepto de isotopía por parte de Greimas y Courtés (1990): "la recurrencia de categorías sémicas, sean estas temáticas (o abstractas) o figurativas” (p. 230). Este proceder discursivo remonta sus raíces hasta la epopeya, tal como lo describe Ramos (1988), bajo la categoría de idiosincrasia del epos: "Es un lenguaje esencializador: sólo dice lo que debe decir a fin de que un agonista surja tal cual es en el mundo" (p. 110). Este lenguaje esencializador, que según Ramos (1998), puede mostrarse "al nivel de "un sustantivo, o de una frase, o al nivel más complejo de un episodio" (p. 110), se revela de modo carnavalesco en los trabajos de Samper Ospina; en efecto, en la muestra considerada, se configuran, con el correr de los textos, lugares comunes que, de tanto reiterarse, se impregnan como segunda piel a la caracterización de los personajes. Para ilustrar esto, observaremos en el siguiente cuadro, un breve seguimiento isotópico (no exhaustivo) a uno de los tantos personajes representativos de la política colombiana4 sobre quienes el autor ha trazado un bien definido epos carnavalesco: Francisco Santos.

- Oístes, me voy al baño, estoy que me reviento. No, mirame este bizcocho. Está peor que como lo dejaba Yidis en Palacio. Tengo que trapear. ¿Ahora con qué trapeo? Me toca llamar a Pacho (Las revelaciones de alias Cupido, el 'hacker' de Uribe que chuzaba corazones, 13 de diciembre de 2014).

- Jamás he dado trato de sirviente al doctor Francisco Santos, y eso lo puede certificar él mismo, una vez me suba el desayuno (Los puntos del memorial de agravios de Uribe que nadie ha publicado, 9 de mayo de 2015).

- Prohíbe, eso sí, la caza de pokémones durante la marcha, para proteger a Pacho Santos: cualquiera podría equivocarse de muñeco (Cartilla de educación sexual aprobada por el CD, Ordóñez y Viviane Morales, 13 de agosto de 2016).

Asistimos aquí a un proceso de largo aliento del que dan cuenta las fechas de publicación, durante el cual el autor - de alusión en alusión, de digressio en digressioconstruye la entronización bufa de un personaje ataviado por las isotopías del servilismo y la imbecilidad, tan caras al carnaval. Ese lenguaje esencializador, que con la epopeya nos regaló apósitos heroicos inolvidables (Andrómaca, la de níveos brazos; Patroclo, el más amado de los compañeros; Aquiles, el de los pies ligeros; Odiseo, el astuto...), nos ofrece ahora, en clave de ironía, nuevos epítetos, auspiciados, en este caso, por las metáforas de sirviente, mascota y muñeco. Esta característica de "decir lo más con lo menos" (Ramos, 1988, p. 115) bien puede dialogar con el arte de la alusión que, de acuerdo con Jankélévitch (2012), se constituye en la esencia argumentativa de la ironía, pues esta "sabe que no hace falta decirlo todo y ha renunciado a ser exhaustiva: tiene confianza en el oyente para levantar el sentido con la palanca del signo, en la percepción para completar con recuerdos las señales de la sensación” (p. 95).

\footnotetext{
4 Similar ejercicio se puede adelantar en torno a otros personajes de la política como Álvaro Uribe Vélez, quien ha sido tema de trabajos como los de Hernández (2015) y Arrieta (2013).
} 
1.1.4 Una peroratio rizomática: desde la época del esplendor retórico hasta nuestros días, el cierre del discurso representa para el autor el reto de darle punto final a un circuito comunicativo, volviendo a la tesis y moviendo al oyente/lector después de haberlo convencido. De este modo, la peroratio -según lo expresan Alvarado y Yeanoteguy (2000) - trae consigo "un golpe de efecto, un fragmento destinado a permanecer en la memoria del auditorio por su patetismo, su emotividad o su contundencia” (p. 73). Ahora bien, contraria al epílogo canónico, la peroratio en las columnas irónicas revisadas se comporta de otra forma. Si bien el cierre en los artículos tradicionales, por fuerza de coherencia, se podría asimilar al de un árbol que vuelve a beber de sus propias raíces, el epílogo de estos textos irónicos se nos muestra como rizoma (Deleuze \& Guattari, 2000), como un fruto salido de donde menos se esperaba o como vuelta de tuerca con final divergente inspirado en algún detalle marginal que había sido dejado por el autor en algún punto de su texto. Por ejemplo, en el texto Uriber: una alianza entre Uber y Uribe (17 de octubre de 2015), el locutor ha expuesto dos conjeturas sobre el posible nombre - Uber Riascos- tanto del conductor de una camioneta como de un colega con quien habla el taxista que lo conduce al trabajo. Lo cierto es que, más allá de la homonimia de este nombre con el acrónimo de la empresa internacional de transporte privado, el detalle resulta marginal y lejano de la macroestructura textual. Sin embargo, Samper Ospina, tal como lo ha hecho en el $79 \%$ de las columnas aquí examinadas, se desliza hacia el cierre con un apunte rizomático, imprevisible para el lector:

[...] Pero será emocionante ver a los senadores uribistas con camisetas que digan "Lo que es con 'Uriber' es con todos"; y a los amarillos respetando, por primera vez, los carros blancos. Porque con el doctor Uribe de por medio, cualquier taxista sabe que el asunto es a otro precio. Y cuando digo cualquiera, es cualquiera: hasta Uber Riascos (Uriber: una alianza entre Uber y Uribe, 17 de octubre de 2015)

Aquí el autor rehúye el cierre esperado de volver a la tesis y sorprende a su lector con una carta cualquiera que brota de la manga. En medio de esta irrupción discursiva que nos toma por sorpresa, Jankélévitch (2012) nos puede aportar algunas pistas, ya que "el ironista no quiere ser profundo, el ironista no quiere adherirse, ni tener peso, pero toca el pathos con una tangencia infinitamente tenue y casi imponderable" (p. 37). Este arte del roce - propio de una peroratio que rehúye las coherencias y los cánones- nos recuerda, también con Jankélévitch, que "la conciencia irónica no desea apretar, prefiere mariposear de anécdota en anécdota, de placer en placer, y probar de todo sin posarse en ninguna parte" (p. 37). 


\subsection{Una dispositio argumentativa travestida}

En el corpus estudiado, la ironía, en su calidad de detonadora de sentidos, puede ser dibujada desde la metáfora del caballo de Troya, ya que en un $65 \%$ de la muestra se consigue una mimetización de formas y estructuras de géneros, distintos de la columna de opinión clásica, en función de una intención carnavalesca. Se aprecia cierto tipo de travestimiento textual que, en principio, se puede asimilar a la definición original de Genette (1989) en términos de "transformación estilística con función degradante" (p. 37), pero que posteriormente puede ampliarse al fenómeno de travestimiento de géneros que Caro y Castrillón (2011) identificaron como uno de los procedimientos irónicos preferidos por el grupo Les Luthiers y que se caracteriza por "quiebres estilísticos, permutaciones abruptas entre tipologías, inversiones enunciativas y cambios de tonalidad" (p. 14). En el caso de Samper Ospina, el corpus ofrece diálogos (16 textos), crónicas familiares (12), testimonios (7), cuentos (6), reportajes (5), crónicas mundanas (3), noticias (2), diarios íntimos (2), clases magistrales (2), obras de teatro (2), himnos (1), cartillas (2), instrucciones (1), textos explicativos (1) y contratos laborales (1).

Ante este fenómeno, una vez más podemos ratificar las nuevas tesis que, desde una perspectiva pragmática (Sperber \& Wilson, 1981; Schoentjes, 2003; Ducrot, 1988; Ruiz-Gurillo, 2012; y Torres-Sánchez, 2009, entre otros), superan las tradicionales concepciones en torno a la ironía como simple figura de ornato o como simple antífrasis que reproduce lo contrario de lo que se dice. Podemos vislumbrar que la ironía, al estilo de un nuevo caballo de Troya, penetra en las comunidades discursivas, camuflada de las superestructuras mejor instituidas, para propiciar, por dicho contacto, los más diversos efectos perlocutivos. Podemos afirmar que la ironía, en estas columnas de opinión, se comporta, a efectos de la infraestructura textual, como un fenómeno intertextualizado, travestido y carnavalizado, lo que por fuerza nos hace retomar a Bajtín (1976); en efecto, él hablaba de dos vidas: de un lado, la oficial, "monolíticamente seria y limitada, sometida a un orden jerárquico rígido, penetrado de dogmatismo, de temor, de veneración, de piedad" (p. 323); y del otro, la de carnaval, "de plaza pública, libre, llena de risa ambivalente, de sacrilegios, de profanaciones, de envilecimientos, de inconveniencias, de contactos familiares con todo y con todos” (p. 323). Quizás, podríamos hablar, en términos similares, de dos vidas textuales en el género de la columna de opinión: la primera (la de la mayoría de autores), la oficial, la seria, sometida a una dispositio canónica que, así permita ciertos juegos, responde a unas necesidades comunicativas situadas en una época y en una cultura determinadas; y la segunda (la de Samper Ospina), la de carnaval, la de plaza pública: polifónica, hibridada, rizomática, digresiva, irreverente $y$ provocadora... la vida textual de la ironía. 


\section{Los mecanismos de textualización}

Bronckart (2004) define estos mecanismos como series isotópicas que contribuyen a establecer la coherencia temática. "Son parte fundamental de la articulación lineal del texto y explicitan ante los destinatarios las grandes articulaciones jerárquicas, lógicas y/o temporales" (p. 77). Allí se inscriben los mecanismos de conexión, los de cohesión nominal y los de cohesión verbal. Para el análisis del corpus, y a tono con los últimos trabajos sobre ironía, abordaremos este nivel desde el modelo neogriceano que propone el grupo Griale de la Universidad de Alicante (RodríguezRosique, 2009). Basada en las máximas conversacionales de Levinson, RodríguezRosique (2009), a nombre del grupo, postula que "la ironía es una consecuencia de la violación explícita, por parte del hablante, y con el correspondiente reconocimiento de su interlocutor, de la máxima de cualidad” (p. 128). Rastreemos, entonces, el comportamiento de las columnas revisadas en términos de las inversiones a los principios de cantidad, informatividad y manera.

\subsection{Inversiones al principio de cantidad}

De acuerdo con el principio de Levinson de no proporcionar una información más débil que el conocimiento del mundo que se posee, Ruiz-Gurillo (2012) explica que "ciertos indicadores irónicos como los cuantificadores, determinados sufijos o los encomiásticos se infieren contextualmente de manera negativa" (p. 116). Esto puede verse a lo largo de toda la muestra; miremos, por ejemplo, el siguiente caso:

[...] Detrás de un proyecto tan pío está gente Uno A, como Richard Aguilar: aquel joven gobernador, heredero de una bonita estirpe acusada un poquito de violencia, un poquito de paramilitarismo, cuyo avión mató a un muchacho al aterrizar folclóricamente cerca de la cárcel en que pernocta su papá (Parque temático 'Alejandro Ordóñez Maldonado', 6 de diciembre de 2014).

Sin duda, la bomba irónica que invierte el principio de cantidad se detona por la cercanía de tantos encomiásticos juntos ("pío", "Uno A", "bonita"), en contacto con el cuantificador "poquito" adosado a sustantivos de tanto peso - no cuantificables- como "violencia" y "paramilitarismo", y con el auxilio del adverbio "folclóricamente" aplicado con impropiedad (Attardo, 2000) al hecho repudiable, per se, de la muerte de una persona, por culpa de un aterrizaje de un avión cerca de la cárcel en la que está preso (en grado menor, "pernocta") el papá de Aguilar. Salta a la vista cómo dictum y modus corren por lechos distintos y colisionan irónicamente: el primero acumula un prontuario delictivo (violencia + paramilitarismo + muerte de una persona + aterrizaje irregular + padre encarcelado), mientras que el segundo califica los hechos inusitadamente de modo positivo (pío + Uno A + bonita + poquito + poquito + folclóricamente + pernoctar). En pocas palabras, este modus no aplica, en absoluto, a tal dictum. Tal unión solo la consiente el carnaval de la ironía. 


\subsection{Inversiones al principio de informatividad}

Desde la base del principio de informatividad, que para Levinson consiste en proporcionar la información mínima suficiente para la consecución de los propósitos comunicativos, recuerda Ruiz-Gurillo (2012) que la ironía consigue profundas inversiones, en virtud de fenómenos como la polisemia o la homonimia (p. 116). Podríamos decir que esta es la inversión más visible; un ejemplo de tantos es el siguiente:

[...] Pero la verdad es que, provocado por Uribe, Santos se convirtió en el Real Madrid de la política, dispuesto él también a salirse de Casillas (Presidente Santos: idesescale el lenguaje!, 1 de agosto de 2015).

La antonomasia que el autor adjudica a Santos como "el Real Madrid de la política" se instala sobre la ambigüedad que suscita, ante todo en el plano sonoro, la expresión "salirse de casillas", aplicable, tanto a la locución coloquial de "perder la calma", como al hecho - vigente en ese momento para el equipo en cuestión- de querer excluir de su nómina al arquero Iker Casillas. Este procedimiento discursivo y otros que, por su extensión, no podríamos explicar aquí 5 , le dan la razón a Rodríguez-Rosique (2009) cuando destaca que "la inversión del Principio de Informatividad es un recurso muy explotado por los hablantes que buscan resultados humorísticos, pues la multiplicación de referentes es la principal responsable de los dobles sentidos" (p. 122).

\subsection{Inversiones al principio de manera}

El principio de manera, que consiste, según Levinson, en indicar una situación normal mediante expresiones no marcadas, se invierte a través de "cambio de registro, empleo de fraseología o de ciertas figuras retóricas como la metáfora o la hipérbole” (Ruiz-Gurillo, 2012, p. 116). Un ejemplo de ello, en la prosa de Daniel Ospina, es el siguiente ${ }^{6}$ :

\section{[...] Con todo, hay que reconocer que Uribe es inflamable únicamente en tanto contradictor,}

\footnotetext{
5 Es el caso de homonimias, pseudoabarcadores, calambures, antanaclasis, correctios, pretericiones, homofonías, oxímoros, retruécanos, paradojas, paralelos, repeticiones, anfibologías, correctios, perífrasis, anacronismos, epíforas, expolitios, anáforas, reduplicaciones, preguntas retóricas, prosopopeyas, símiles, quiasmos, reticencias y alegorías..., que también incidirían en la inversión de este principio de informatividad.

6 Del mismo modo, por razones de espacio, no incluimos en este artículo ejemplos de cambios de registro, desautomatizaciones fraseológicas, paronomasias, metáforas, fraseologías, paragoges, apócopes, ditologías, cacofonías, defraudaciones obscenas, reticencias, acrónimos caricaturescos, sufijación irónica, lítotes, deprecaciones, sermocinatios, hipérboles, parodias, antonomasias, hipérboles, prosopografías, etopeyas, traducciones homofónicas y topografías. Todos estos recursos contribuyen a la inversión de este principio de manera.
} 
porque si algún mandatario colombiano supo desescalar el lenguaje, al menos mientras gobernó, ese fue Uribe: en lugar de decir "callate a ver, periodista maluco, o te voy es partiendo, papá”, sugería, con amabilidad: "otra pregunta, amigo periodista” [1]. En lugar de afirmar, vehemente, "ese tipo era un paraco impresentable que coleccionaba armas desde chiquito, pero lo nombré en el gobierno porque éramos amigos y yo me quedaba a dormir en su casa y todo", sugería, suave, "Jorge Noguera es un buen muchacho" [2]. Incluso, en vez de acudir a expresiones prosaicas como "esos son campesinos que el Ejército asesinó por si acaso", afirmaba, poético, "esos muchachos no estarían recogiendo café" [3] (Presidente Santos: idesescale el lenguaje!, 1 de agosto de 2015).

Aquí los giros eufemísticos [1], las omisiones sinecdocales [2] y los cambios de registro con lítotes incluida [3] introducen expresiones marcadas que, para efectos irónicos, inoculan argumentaciones sarcásticas en contra de la víctima de la ironía. En este caso, el personaje aparentemente defendido por desescalar el lenguaje se convierte, gracias a la inversión del principio de manera, en acusado por sus propias palabras.

En suma, podríamos concebir el nivel de los mecanismos de la textualización como un tejido de procedimientos pragmalingüísticos, gracias a los cuales se invierten los principios de cantidad, informatividad y manera, al servicio de intenciones irónicas que reconfiguran el sentido de los enunciados, lo que, a la postre, carnavaliza la máxima de cualidad alrededor de la cual Grice (1983) y Levinson (2004) supeditan el sentido de la comunicación humana (y obviamente, el deber ser de una columna de opinión): decir siempre la verdad.

\section{Los mecanismos de asunción del compromiso enunciativo}

Acerca de este nivel, sostiene Bronckart (2004) que sus mecanismos participan en la realización de la coherencia pragmática del texto, desde dos frentes: el primero, desde "la clarificación de las responsabilidades enunciativas (¿cuáles son las instancias que asumen lo enunciado en el texto?, ¿qué voces se expresan en él?)”; y el segundo, desde "las diversas evaluaciones (juicios, opiniones, sentimientos) que se reformulan con respecto a ciertos aspectos del contenido temático" (p. 82). En este estudio optamos por el primer frente, para lo cual apelamos a la propuesta de Ducrot (1988), en la que se articulan el dialogismo y el carnaval bajtinianos, a la vez que se propone una simbiótica relación entre la polifonía y el humor7.

\footnotetext{
7 Recordemos que Ducrot (1988) califica de humorístico al enunciado que cumpla con las tres condiciones siguientes: a. Entre los puntos de vista representados en el enunciado, por lo menos, hay uno que obviamente es absurdo, insostenible (en sí mismo o en el contexto); b. El punto de vista absurdo no es atribuido al locutor; c. En el enunciado no se expresa ningún punto de vista opuesto al punto de vista absurdo (no es rectificado por ningún enunciador) (p.
} 
En esta dinámica, nos interesa reconocer las diferencias entre locutor, como responsable del enunciado, y enunciador, como cada uno de los diferentes puntos de vista que se presentan en el enunciado. En el caso de las columnas de Samper Ospina, avistamos, al menos, cuatro escenarios:

- El primero se advierte en la forma de suscribir la función locutor. Si bien el $69 \%$ de los textos ofrece como presunto locutor al autor de la columna, un $31 \%$ trae como locutores a quienes serán las víctimas de su ironía (Álvaro Uribe, Juan Manuel Santos, Alejandro Ordóñez, Andrés Pastrana...) o a locutores irreales (el exorcista de Paloma Valencia, un terapista para adictos al poder, la secretaria que contestará el teléfono de la fiscalía...) o a locutores traídos de la ficción (dos extraterrestres que visitan a Colombia o el jefe de la serie Misión Imposible).

- El segundo se aprecia en la manera como el yo locutor adquiere función de enunciador absurdo. Esto ocurre en los 69 textos que aparecen bajo la presunta voz de Samper Ospina; por ejemplo: "[...] y no lo digo con ánimo de ofender a nadie, mucho menos al doctor Uribe, de quien he sido hincha desde sus épocas de samperista" (Propuesta para desmovilizar al uribismo, 15 de agosto de 2015). Aquí, al contrario de lo que ocurre en el género de la columna de opinión, al yo autor del texto no podrían atribuirse las palabras del yo locutor.

- El tercero, en cambio, presenta enunciados con los que el locutor se identifica plenamente; por ejemplo, en el texto anteriormente citado, más adelante aparece: "De manera que no lo digo por ofender, que quede claro, sino porque sueño con que Colombia alcance la paz, y la paz no se puede lograr con el doctor Uribe empeñado en incendiarla" (Propuesta para desmovilizar al uribismo, 15 de agosto de 2015).

- El cuarto desestabiliza aún más, en nombre de la carnavalización irónica, la consistencia enunciativa al introducir en las voces de los enunciadores toda suerte de contenidos absurdos; por ejemplo:

[...] a través de una carta enviada al diario El Tiempo, un grupo de ciudadanos notables, encabezados por William Ospina, propuso que la exitosa fórmula que disparó a la gloria el balompié nacional se repita en otros ámbitos nacionales, como el de la política, y contratemos entre todos a un presidente extranjero, libre de intrigas partidistas e impasible ante la prensa cizañera (Por Colombia, gane o pierda, 5 de julio de 2014).

20). Dentro de los enunciados humorísticos -agregará más adelante Ducrot- se calificarán de irónicos "aquellos en que el punto de vista absurdo es atribuido a un personaje determinado, que se busca ridiculizar” (p. 21). 
Ante este panorama, y de regreso a la propuesta de Ducrot, observamos que en los textos examinados: 1. Muy pocos enunciados contienen la función locutor; lo que arroja que el yo locutor muy pocas veces coincida con el yo autor; 2. La gran mayoría de los enunciados revelan las funciones de enunciador absurdo y enunciador irónico; 3. Casi todo el contenido que arrastran las voces citadas por el texto no se puede atribuir a los autores allí mencionados. Esto invierte de forma carnavalesca las tradiciones enunciativas de un género discursivo como el de la columna de opinión, en el cual la función locutor es claramente definida, las voces de los enunciadores se sustentan en la fiabilidad, y son fáciles de inferir las cercanías o las distancias entre lo que dicen los enunciadores y lo que acepta el locutor.

\section{A modo de conclusión}

Del análisis expuesto, podríamos colegir que el ejercicio de rastrear una arquitectura textual -desde las condiciones del interaccionismo sociodiscursivo- en las columnas de Daniel Samper Ospina propicia nuevas posibilidades de abordar la comprensión de los textos argumentativos irónicos, en medio de los distintos rumbos que marca la investigación sobre la ironía verbal, más allá de las atomizadas formas de una simple condición antifrástica o de simple figura de ornato. Así, a la ironía como eco (Sperber \& Wilson, 1981), como argumento (Sopeña-Balordi, 1997), como superestrategia (Alba-Juez, 2002), como categoría prototípica (Kalbermatten, 2006), como implicatura conversacional particularizada (Rodríguez-Rosique, 2009), como polifonía (Bruzos-Moro, 2009) y como detonadora de creatividad (Huang, Gino \& Galinsky, 2015), quisiéramos añadir la ironía como dispositivo textual carnavalizante. Tal condición genera una arquitectura textual sui generis en la que afloran las mixturas y las hibridaciones: desde el carnaval de las formas de argumentar (con exordios ponzoñosos, narratios evaluativas, argumentatios caricaturescas y peroratios rizomáticas) hasta el travestimiento con otras formas del decir (relatar, narrar, describir y exponer). Asimismo, nos hace constatar, en el plano de la textualización, las más diversas inversiones a los principios de la cantidad, la informatividad y la manera, gracias al poder que ejercen los encomiásticos, los cuantificadores, las polisemias, las caricaturizaciones, las homonimias, las antonomasias, las ambigüedades, las hipérboles, los cambios de registro, las lítotes y tantos otros, puestos en clave irónica en el corazón de las cohesiones textuales. Y por último, en el ámbito de la responsabilidad enunciativa, nos hace discernir polifonías en diversos sentidos, gracias a la irrupción inesperada de enunciadores absurdos que ocupan todo el espectro textual, desde la autoría hasta la fuente citada, lo que pone en crisis las respuestas por el quién habla allí y con quién se identifica el locutor. 
Seguramente, si intentamos comparaciones con la arquitectura textual de la columna de opinión tradicional, nos asombremos de las diferencias que aquí despuntan. Y en efecto, al contacto con una arquitectura textual irónica tan peculiar, tan voluble en sus niveles, tan inestable en sus formas, tan carnavalizada en sus principios, solo podríamos encontrar explicación en Jankélévitch (2012); para él, con toda razón, "la ironía es el poder de jugar, de volar por los aires, de hacer malabarismos con los contenidos, ya sea para negarlos o para recrearlos” (p. 19). Así, la arquitectura textual de la ironía es el poder de jugar con las tipologías y los géneros; el poner a volar por los aires los principios de la cantidad, la informatividad y la manera; y el hacer malabarismos con las enunciaciones, bien sea para negar los discursos o, mejor aún, para re-crearlos.

\section{Referencias}

Albaladejo, T. (1991). Retórica. Madrid: Síntesis.

Alba-Juez, L. (2002). Análisis de las funciones y estrategias del discurso irónico. (Tesis doctoral). Universidad Complutense de Madrid. Recuperado de http://eprints.ucm.es/3383/

Alvarado, M. \& Yeannoteguy, A. (2000). La escritura y sus formas discursivas. Buenos Aires: Universitaria.

Aristóteles (2005). El arte de la retórica. Buenos Aires: Eudeba.

Arrieta, L. (2013). La construcción de los sujetos en el discurso del expresidente Uribe Vélez: un análisis desde las tonalidades valorativas y los actos de habla. Cuadernos de Lingüística Hispánica, (21), 103-116.

Attardo, S. (2000). Irony as Relevant Inappropriateness. Journal of Pragmatics, 32, 793-826.

Bajtín M. (1976). Carnaval y Literatura. Revista Eco, (134), 311-338.

Bergson, H. (2008). La risa. Ensayo sobre la significación de lo cómico. Madrid: Alianza.

Boyd-Swan, F. (2009). Cómo se manifiesta la ironía en un texto escrito. En L. RuizGurillo \& X. Padilla-García (eds.), Dime cómo ironizas y te diré quién eres (pp. 293-305). Universidad de Alicante: Peter Lang.

Bronckart, J. P. (2004). Actividad verbal, textos y discursos: por un interaccionismo sociodiscursivo. Madrid: Fundación Infancia y Aprendizaje. 
Bruzos-Moro, A. (2009). La polifonía. En L. Ruiz-Gurillo \& X. Padilla-García (eds.), Dime cómo ironizas y te diré quién eres (pp. 45-64). Universidad de Alicante: Peter Lang.

Caro, M. \& Castrillón, C. (2011). Burlemas e infortunios en la ironía de Les Luthiers. Pereira: Universidad Tecnológica de Pereira.

Caro, M., Camargo, Z. \& Uribe, G. (2018). La ironía re-visitada en sus dimensiones pragmáticas, comprensivas, discursivas y didácticas. Lenguaje, 46(1), 95-126.

Crespo, V. (2008). Las claves argumentativas de la ironía: Una aproximación argumentativa al fenómeno irónico. (Informe para el Diploma de Estudios Avanzados). Universidad de Alicante, España.

Deleuze, G. \& Guattari, F. (2000). Rizoma. Madrid: Pre-textos.

Dolz, J. \& Schneuwly, B. (1997). Géneros y progresión en expresión oral y escrita. Elementos de reflexión a partir de una experiencia realizada en la Suiza francófona. Textos de Didáctica de la Lengua y de la Literatura, (11), 77-98.

Ducrot, O. (1988). Polifonía y argumentación. Conferencias del seminario Teoría de la Argumentación y Análisis del Discurso. Cali: Universidad del Valle.

Genette, G. (1989). Palimpsestos: la literatura en segundo grado. Madrid: Taurus.

Greimas, A. J. \& Courtés, J. (1990). Semiótica. Diccionario razonado de la teoría del lenguaje. Madrid: Gredos.

Grice, H. (1983). La lógica y la conversación. En Lenguaje y Sociedad (pp. 101-122). Cali: Centro de Traducciones, Universidad del Valle.

Hernández, N. (2015). La construcción mediática de perdedores y vencedores en el campo político: análisis de las metáforas, tópicos y lexicalización. Cuadernos de Lingüística Hispánica, (25), 81-98.

Huang, L., Gino, F. \& Galinsky, A. (2015). The Highest Form of Intelligence: Sarcasm Increases Creativity for Both Expressers and Recipients. Organizational Behavior and Human Decision Processes, 131, 162-177.

Jankélévitch, V. (2012). La ironía. México: Me cayó el veinte.

Kalbermatten, M. (2006). Verbal Irony as a Prototype Category in Spanish: A Discoursive Analysis. (Tesis doctoral). University of Minnesota, USA. 
Levinson, S. (2004). Significados presumibles: la teoría de la implicatura conversacional generalizada. Madrid: Gredos.

Martínez-Egido, J. (2014). El humor en el artículo de opinión. Feminismo/s, 24, 117-141.

Mier, F. (2017). El papel del contexto en la comprensión de la ironía verbal. Análisis pragmático de una muestra. Enunciación, 22(1), 28-42.

Pujante, D. (2003). Manual de retórica. Madrid: Castalia.

Ramos, O. (1988). Categorías de la epopeya. Bogotá: Instituto Caro y Cuervo.

Rodríguez-Rosique, S. (2009). Una propuesta neogriceana. En L. Ruiz-Gurillo \& X. Padilla-García (eds.), Dime cómo ironizas y te diré quién eres (pp. 109-132). Universidad de Alicante: Peter Lang.

Ruiz-Gurillo, L. (2012). La lingüística del humor en español. Madrid: Arco/Libros.

Ruiz-Gurillo, L., Marimón-Llorca, C., Padilla-García, X. \& Timofeeva, L. (2004). El proyecto GRIALE para la ironía en español: conceptos previos. Estudios de Lingüística Universidad de Alicante, (18), 231-242.

Schoentjes, P. (2003). La poética de la ironía. Madrid: Cátedra.

Sopeña-Balordi, E. (1997). El concepto de ironía: de tropo a ambigüedad argumentativa. Revista de Filología Francesa, (12), 451-460.

Sperber, D. \& Wilson, D. (1981). Irony and the Use-Mention Distinction. En P. Cole (ed.), Radical Pragmatics (pp. 295-318). New York: Academic Press.

Torres-Sánchez, M. A. (2009). La relevancia. En L. Ruiz-Gurillo \& X. Padilla-García (eds.), Dime cómo ironizas y te diré quién eres (pp. 65-87). Universidad de Alicante: Peter Lang. 